\title{
40 NĂM ƯơM MẦM TRI THỨC VÀ GẮN BÓ NHỮNG ÂN TÌNH
}

- NGUTT. PGS, TS. Nguyễn Văn Đệ Bí thu Đảng uỷ, Hiệu trưởng Trường Đại học Đồng Tháp

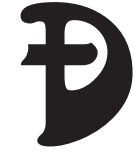
ối với thế hệ cán bộ, giảng viên và học viên, sinh viên Trường Đại học Đồng Tháp, ngày Nhà giáo Việt Nam 20/11 năm nay có ý nghĩa rất đặc biệt. Bởi vì đó là ngày diễn ra "cuộc hội ngộ của 40 năm”, các thế hệ thầy - trò tay trong tay, vai bên vai, rưng rưng cảm xúc.

Gần hơn một nửa đời người, nối giữa hai thế kỷ, cảnh vật đổi thay xoay vần theo vòng quay con tạo, hình dung của mỗi người cũng "biến thiên" theo sắc màu thời gian, nhưng ân tình thì vẫn còn mãi, vẹn nguyên và tươi tắn như "mùa xuân đầu tiên".

Cuộc hành trình 40 năm (1975-

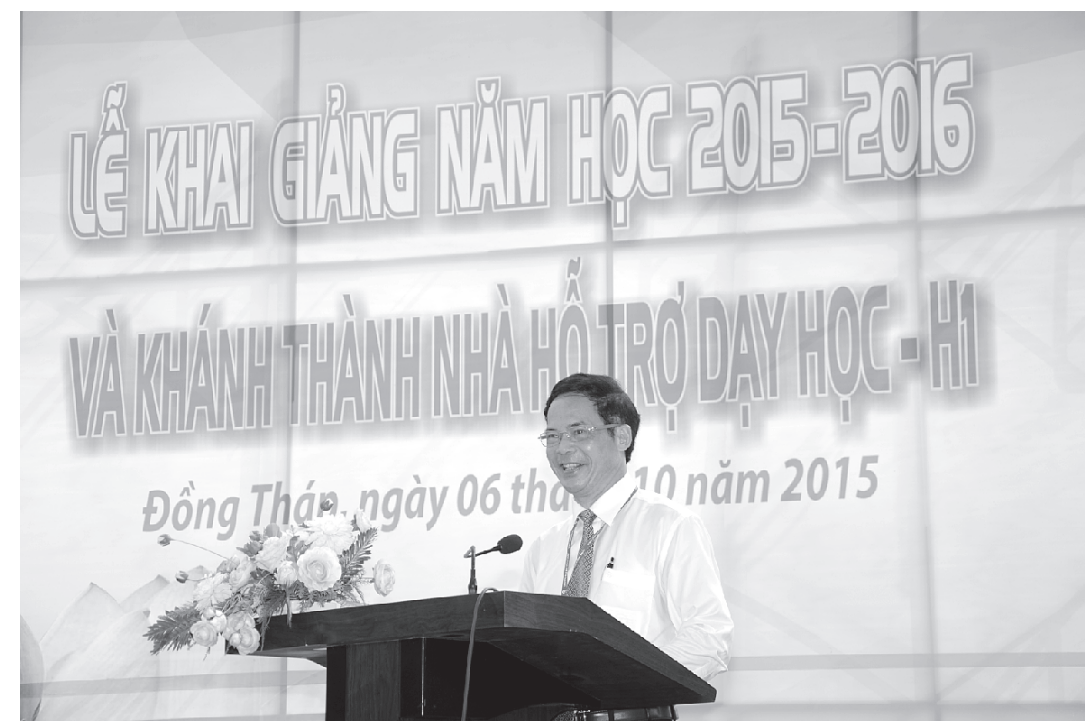

NGUT. PGS,TS. Nguyễn Văn Đệ 2015) ấy cũng đánh dấu những thành tựu đáng trân trọng của tập thể các thế hệ cán bộ, giảng viên và học viên, sinh viên Trường Đại học Đồng Tháp suốt dọc chiều dài thời gian, trên quê hương vùng đất Sen hồng.

\section{Trưởng thành từ mô hình trường sư phạm đa cấp đầu tiên cả nước}

Nhớ lại, cách nay gần 40 năm, sau ngày miền Nam hoàn toàn giải phóng, trước yêu cầu thiết lập các trường đào tạo giáo viên phổ thông và mầm non ở vùng đất lịch sử Đồng Tháp Mười, vào ngày 26/12/1975, theo Quyết định của Bộ Giáo dục và Thanh niên, Trường Trung học Sư phạm Đồng Tháp được thành lập và khai giảng khóa cấp tốc đầu tiên.

Năm 1977, Ủy ban nhân dân (UBND) tỉnh Đồng Tháp quyết định thành lập Trường Sư phạm Cấp II Đồng Tháp. Đến năm 1984, Hội đồng Bộ trưởng (nay là Chính phủ) quyết định công nhận Trường Sư phạm Cấp II Đồng Tháp là Trường Cao đẳng Sư phạm Đồng Tháp.

Đồng thời, trong giai đoạn này, UBND tỉnh Đồng Tháp ra quyết định thành lập Trường Sư phạm Mẫu giáo Đồng Tháp (năm 1980), Trường Cán bộ quản lý giáo dục Đồng Tháp (năm 1985). Năm 1989, Tỉnh ủy, UBND tỉnh Đồng Tháp đã cho hợp nhất các trường đào tạo giáo viên và cán bộ quản lý giáo dục trong Tỉnh thành một trường lấy tên là Trường Cao đẳng Sư phạm Đồng Tháp. Đây là mô hình trường sư phạm đa cấp đầu tiên trong cả nước.

Đến năm 2003, trước yêu cầu đào tạo giáo viên và cán bộ quản lý giáo dục cho vùng Đồng bằng sông Cửu Long, Trường Đại học Sư phạm Đồng Tháp được thành lập trên nền tảng Trường Cao đẳng Sư phạm Đồng Tháp, theo Quyết định số 08/2003/QĐ-TTg ngày 10/01/2003 của Thủ tướng Chính phủ. Đến ngày 04/9/2008, Trường Đại học Sư phạm Đồng Tháp đổi tên thành Trường Đại học Đồng Tháp - một trường đại học đa ngành, đa cấp, đa hệ.

Những ngày đầu dựng trường, mở lớp, mặc dù trong hoàn cảnh khó khăn khắc phục vết thương chiến tranh, nhưng được sự quan tâm của Đảng và Nhà nước, sự thương yêu đùm bọc của người dân, sự chi viện và giúp đỡ chí tình của các cơ sở giáo dục miền Bắc, bằng sự phấn đấu không mệt mỏi của các thế hệ cán bộ, giảng viên, sinh viên, học sinh, nhà trường đã vượt qua muôn vàn khó khăn thử thách để thực hiện nhiệm vụ đào tạo từ các hệ cấp tốc, $9+1,9+2,9+3,12+1,12+2$ cho đến cao đẳng, đại học và sau đại học như ngày hôm nay. 
Chủ trương trong giai đoạn đầu của các trường sư phạm lúc đó là vừa tổ chức đào tạo vừa lao động tăng gia sản xuất, với các hoạt động "cắt lúa, đóng gạch, trồng tràm, bốc sắt, dệt chiếu", tuy cực mà vui, được nhắc đến như những huyền thoại cho đến ngày nay. Trong khó khăn đó, thầy trò đều tự vượt lên và gắn kết nghĩa tình. Gần bốn thập kỷ trôi qua, các thế hệ cán bộ, giảng viên, học viên và sinh viên Trường Đại học Đồng Tháp luôn kế thừa, phát huy truyền thống vẻ vang, đoàn kết đồng lòng để thực hiện tốt sứ mệnh được giao.

Với truyền thống 40 năm đào tạo giáo viên và cán bộ quản lý giáo dục, Nhà trường đã góp phần to lớn trong việc bổ sung hơn 40.000 giáo viên, cử nhân và cán bộ khoa học - kỹ thuật đóng góp thiết thực vào sự phát triển kinh tế - xã hội của Đồng Tháp, các tỉnh vùng Đồng bằng sông Cửu Long và cả nước.

\section{Khẳng định vị thế trong sự nghiệp đổi mới căn bản, toàn diện giáo dục và đào tạo}

Đến tháng 11/2015, Trường Đại học Đồng Tháp được giao nhiệm vụ đào tạo trình độ thạc sĩ với 5 chuyên ngành: Quản lý giáo dục, Lý luận và Phương pháp dạy học bộ môn Toán, Giáo dục học (Giáo dục Tiểu học), Ngôn ngữ Việt Nam, Hóa lý thuyết và Hóa Lý. Trường hiện có 32 ngành đào tạo trình độ đại học, 16 ngành đào tạo trình độ cao đẳng. Quy mô đào tạo của nhà trường hiện nay 10.600 học viên, sinh viên chính quy đến từ 49 tỉnh, thành trong cả nước và cùng với 4.600 sinh viên hệ liên thông, vừa làm vừa học tại 22 cơ sở đào tạo thuộc các tỉnh trong và ngoài vùng Đồng bằng sông Cửu Long.

Ngoài ra, nhà trường còn liên kết với nhiều trường đại học có uy tín trong nước để đào tạo trình độ thạc sĩ với 460 học viên, hiện đang là giảng viên, giáo viên, cán bộ thuộc các trường đại học, cao đẳng, trường phổ thông, các doanh nghiệp trong và ngoài vùng Đồng bằng sông Cửu Long. Cũng qua 40 năm truyền thống, 1.260 sinh viên ưu tú của Trường đã được kết nạp vào Đảng Cộng sản Việt Nam.

Về đội ngũ, tính đến thời điểm hiện tại, Trường Đại học Đồng Tháp có 586 công chức, viên chức, $89,9 \%$ giảng viên có trình độ từ thạc sĩ trở lên (trong đó có 02 phó giáo sư, 55 tiến sĩ, 75 nghiên cứu sinh, 79 giảng viên đang học tập, nghiên cứu ở nước ngoài). Đặc biệt, Nhà trường đang có 10 cặp vợ chồng giảng viên trẻ, mà cả hai đều là tiến sĩ, hoặc một người là tiến sĩ và một người đang là nghiên cứu sinh.

Đây là sự nỗ lực và thành công vượt bậc của tập thể nhà trường trong 12 năm qua; nhìn lại năm 2003, trường chỉ có 165 cán bộ, giảng viên, với 21 người có trình độ sau đại học. Hiện nay, Nhà trường có 13 khoa đào tạo, 14 phòng - ban chuyên môn, 5 trung tâm, 1 tạp chí khoa học, 1 trạm y tế và 1 trường mầm non trực thuộc.

Trong 40 năm qua, Trường đã có 1.989 đề tài khoa học và công nghệ, công bố 1.345 bài báo trên các tạp chí khoa học có chỉ số ISSN, trong đó có 202 bài báo công bố trên tạp chí khoa học quốc tế với 105 bài báo thuộc danh mục ISI. Từ năm 2012, Bộ Thông tin và Truyền thông đã có quyết định cấp phép hoạt động báo chí in cho Tạp chí Khoa học Đại học Đồng Tháp đến nay đã phát hành 16 kỳ.

Tạp chí Khoa học Đại học Đồng Tháp ra đời với mục đích đăng tải các công trình nghiên cứu khoa học thuộc các lĩnh vực: Khoa học giáo dục và đào tạo giáo viên, Khoa học tự nhiên, Khoa học xã hội và nhân văn, Kinh tế và Công nghệ; thông tin về các kết quả nghiên cứu khoa học trong và ngoài nước nhằm phục vụ công tác đào tạo, nghiên cứu khoa học của trường và của ngành giáo dục. Đó là niềm vinh dự nhưng đồng thời cũng là một trọng trách lớn lao mà Bộ Giáo dục và Đào tạo, Bộ Thông tin và Truyền thông đã tin tưởng giao nhiệm vụ; bước khởi đầu thuận lợi để nhà trường đẩy mạnh công tác nghiên cứu khoa học và ứng dụng khoa học - công nghệ vào đời sống.

Bên cạnh đó, Trường Đại học Đồng Tháp luôn quan tâm thiết lập và phát triển công tác hợp tác quốc tế với nhiều trường đại học, nhiều tổ chức giáo dục và xã hội trong khu vực và trên thế giới. Hoạt động hợp tác quốc tế đã mang lại hiệu quả tích cực cho công tác đào tạo, nhiều cán bộ, giảng viên và sinh viên của trường được tạo điều kiện đi học hoặc tham gia các dự án để nâng cao trình độ chuyên môn và ngoại ngữ tại 10 quốc gia: Úc, Nhật Bản, Hàn Quốc, Pháp, Bỉ, Hà Lan, Trung Quốc, 
Thái Lan, Anh và Mỹ; đồng thời, một số chương trình đào tạo tiên tiến đã được thực hiện trên cơ sở hợp tác với nước ngoài.

\section{0 năm luôn lấy hiệu quả và chất lượng làm nguồn sức mạnh}

Qua 40 năm đào tạo giáo viên và cán bộ quản lý giáo dục (1975-2015), Trường Đại học Đồng Tháp đã xây dựng nên những truyền thống tốt đẹp và quý báu. Đó là lòng nhiệt tình, tâm huyết của các thế hệ cán bộ, giảng viên, sinh viên đối với sự nghiệp giáo dục và đào tạo; tinh thần khắc phục khó khăn, ý thức học hỏi, tự rèn luyện, bồi dưỡng phấn đấu vươn lên trong giảng dạy, học tập, nghiên cứu khoa học; truyền thống đoàn kết, cộng đồng trách nhiệm, sự gắn bó với tập thể của đội ngũ cán bộ, viên chức và sinh viên dưới sự lãnh đạo của Đảng uỷ và Lãnh đạo nhà trường qua các thời kỳ.

Những truyền thống quý báu ấy đã kết tinh thành sức mạnh để xây dựng một môi trường sư phạm tích cực. Trường Đại học Đồng Tháp ngày nay xứng đáng là cái nôi, là bệ phóng vững chãi và đầy tự hào của nhiều thế hệ giáo viên, cán bộ khoa học kỹ thuật, công chức, viên chức, doanh nhân thành đạt đang công tác ở các trường học, cơ quan, đơn vị, doanh nghiệp trong và ngoài tỉnh Đồng Tháp, cùng sự tin tưởng của bà con nhân dân.

Với những thành công đã đạt được, Trường Đại học Đồng Tháp không ngừng nâng cao chất lượng đào tạo, đổi mới phương pháp giảng dạy, đầu tư cơ sở vật chất và trang thiết bị dạy học hiện đại; đặc biệt, chú trọng đến phát triển quy mô đào tạo, song song với việc nâng cao chất lượng đào tạo, bồi dưỡng, mở rộng phạm vi ngành nghề đào tạo ra ngoài sư phạm nhằm đáp ứng nhu cầu nguồn nhân lực của địa phương; tăng cường liên kết đào tạo sau đại học với các đại học, học viện; tổ chức nhiều loại hình bồi dưỡng, đào tạo mới, hiện đại và hiệu quả, tập trung vào những vấn đề thiết thực đang đặt ra cho ngành giáo dục tỉnh Đồng Tháp và vùng Đồng bằng sông Cửu Long; song hành với việc chú trọng xây dựng chương trình đào tạo và bồi dưỡng phù hợp với mục tiêu và đối tượng; đổi mới công tác kiểm tra đánh giá; chú trọng rèn luyện kỹ năng sống, đạo đức nghề nghiệp cho người học.

Và nữa, "đầu tư cơ sở vật chất tốt nhất để phục vụ dạy, học và nghiên cứu" luôn là mong ước thường trực của tập thể lãnh đạo Trường. Chính vì lẽ đó, hai công trình lớn: Nhà Hỗ trợ dạy học và Nhà thí nghiệm thực hành được đầu tư xây dựng và đưa vào sử dụng. Từng ngày, mỗi một hạng mục công trình được hoàn thiện là mỗi một niềm vui nho nhỏ của thầy và trò nhà trường. Sau tất cả và từ tất cả những thành quả trên, cho dẫu vẫn còn "khiêm tốn", nhưng đó là kết tinh của sự nỗ lực, chắt chiu, vun đắp của tập thể Nhà trường.

Với sứ mệnh của mình, Trường Đại học Đồng Tháp luôn lấy hiệu quả và chất lượng đào tạo làm thước đo, làm nguồn sức mạnh để tiếp tục giữ vững và phát huy hơn nữa thành tích tốt đẹp đã đạt được, đẩy mạnh hội nhập để không ngừng phát triển và vươn đến tầm cao mới, làm nòng cốt thúc đẩy sự phát triển của hệ thống giáo dục trong vùng, góp phần tích cực vào sự nghiệp công nghiệp hóa, hiện đại hóa đất nước và đổi mới giáo dục.

\section{Những lời tri ân...}

Nhân dịp kỉ niệm với nhiều cảm xúc này, toàn thể cán bộ, giảng viên và sinh viên của Nhà trường xin bày tỏ lòng biết ơn sâu sắc đối với Đảng, Nhà nước, Ban chỉ đạo Tây Nam Bộ, Bộ Giáo dục và Đào tạo, các Bộ và cơ quan, ban, ngành ở Trung ương, đã quan tâm lãnh đạo, dành những tình cảm sâu nặng và trách nhiệm lớn lao, định hướng cho Nhà trường phát triển bền vững.

Đồng thời, Nhà trường tri ân sâu sắc Đảng bộ, chính quyền và nhân dân các địa phương, nhất là tỉnh Đồng Tháp và các tỉnh, thành phố vùng Đồng bằng sông Cửu Long đã không ngừng kề vai sát cánh ủng hộ, tạo điều kiện giúp đỡ nhà trường trên chặng đường 40 năm qua. Xin được bày tỏ tình cảm trân trọng và biết ơn đối với cộng đồng các trường mầm non, phổ thông, các trường chuyên nghiệp, các trường cao đẳng, đại học trong và ngoài nước; các cơ sở giáo dục, các công ty, doanh nghiệp, các nhà hảo tâm đã giúp đỡ, ủng hộ chúng tôi trên con đường xây dựng hội nhập và phát triển.

Thật vinh dự và rất đỗi tự hào bởi những thành tựu đó, mãi mãi sẽ là tài sản tinh thần to lớn của Trường Đại học Đồng Tháp, ngôi trường được sinh ra và lớn lên nơi vùng đất trung dũng kiên cường của Nam Bộ thành đồng. 
Với những cá nhân đang làm việc tại Trường, chúng tôi luôn khắc ghi những ân tình của các thế hệ lãnh đạo Trường, đồng nghiệp, học viên, sinh viên Nhà trường qua các thời kỳ. "Ân tình” này mang giá trị truyền thống, kết tinh thành văn hóa của Nhà trường. Các thế hệ lãnh đạo Trường, đồng nghiệp, học viên, sinh viên Nhà trường qua các thời kỳ cho dù ở vị trí công tác khác nhau, những hoàn cảnh khác nhau, hay đang ở những địa phương khác nhau... nhưng vẫn luôn quan tâm, luôn dõi theo, luôn giúp đỡ, hỗ trợ cho sự phát triển bền vững của mái nhà chung Đại học Đồng Tháp.

Có những đồng nghiệp đã nghỉ hưu, mái tóc trắng màu mây, đôi mắt hằn sâu những vết chân chim thời gian, chiếc kính ngày một dày thêm, sức khỏe đã không còn được như thời tuổi trẻ vài mươi năm trước, đi lại đã khó khăn hơn... nhưng vẫn dành thời gian, tâm sức và trí lực đóng góp sáng kiến, góp ý một cách chân thành cho kế hoạch chiến lược của Nhà trường. Thật đáng trân trọng biết bao!

Trong những dịp đi công tác, hội nghị, hay đi thực tế ở các địa phương, gặp lại cựu sinh viên của Trường, giờ đã thành đạt ở vị trí công tác nhất định, rồi nghe thêm thông tin vui về những cựu sinh viên khác, chúng tôi thấy ấm áp vô ngần. Mỗi một giải thưởng danh giá mà các bạn sinh viên đang học tại Trường đạt được, mỗi một công trình, bài báo khoa học được công bố, hay mỗi một tân thạc sĩ, tân tiến sĩ bảo vệ thành công luận văn, luận án rồi trở về Trường công tác... đều là niềm vui chung, là sự tự hào chung của tập thể, hòa chung và được nhân lên từ niềm vui của mỗi cá nhân.

Cũng có những đồng nghiệp tài năng đã "xa nhà trường" vì điều kiện gia đình và những hoàn cảnh khác, cũng có những đồng nghiệp tài năng "tìm đến nhà trường" để được làm việc, nghiên cứu và cống hiến... như một sự bù trừ một cách tự nhiên và công bằng.

Hôm nay, chúng tôi dâng trào cảm xúc, khi đang được đứng trên tầng cao nhà $\mathrm{H} 1$ để ngắm nhìn đôi chim én ríu tít bên nhau xây tổ ấm; ngắm nhìn công trình cầu Cao Lãnh đang xây; trong giảng đường bên cạnh, nhiều bạn sinh viên đang say sưa tập giảng những tiết dạy đầu tiên của nghề giáo. Đằng xa, những bước chân khỏe khoắn và dứt khoát của viên chức trẻ đang hành trình trên con đường nội bộ rộng thênh thang... "Chiếc nôi ươm mầm tri thức" vẫn cần mẫn làm việc, để kiến tạo tương lai cho thế hệ trẻ. Trường Đại học Đồng Tháp vẫn thủy chung và sắt son một lòng vì "sự nghiệp trăm năm” bên bờ dòng Tiền Giang hiền hòa, lộng gió.

Đại học Đồng Tháp, tháng 11 năm 2015

Trường Đại học Đồng Tháp là trường đại học công lập, trực thuộc Bộ Giáo dục và Đào tạo, đào tạo đa ngành thuộc các lĩnh vực: sư phạm, kinh tế - kỹ thuật, khoa học - công nghệ, văn hóa - xã hội và nghệ thuật ở các trình độ cao đẳng, đại học và sau đại học; loại hình đào tạo đa dạng với các hệ: chính quy, vừa làm vừa học và liên thông; với sứ mệnh "Đào tạo nguồn nhân lực trình độ cao, đa lĩnh vực, trong đó khoa học giáo dục và đào tạo giáo viên là nòng cốt, nghiên cứu khoa học và cung cấp các dịch vu cộng đồng, góp phần phát triển kinh tế - xã hội vùng Đồng bằng sông Cưu Long”; với hệ giá trị cốt lõi đã được xác lập là: "Chất lượng, Sáng tạo, Hợp tác, Trung thực và Trách nhiệm”.

Với sự nỗ lực không ngừng, Trường Đại học Đồng Tháp đã gặt hái nhiều thành tích đáng tự hào, được Chủ tịch nước tặng thưởng Huân chương Lao động hạng Ba (năm 1985), Huân chương Lao động hạng Nhì (năm 1997), Huân chương Lao động hạng Nhất (năm 2003), Huân chương Độc lập hạng $\mathrm{Ba}$ (năm 2009). Nhà trường cũng đã hoàn thành việc xây dựng và vận hành hệ thống quản lý chất lượng theo tiêu chuẩn ISO 9001:2008 và đã được Trung tâm Chứng nhận phù hợp - QUACERT cấp chứng nhận. Đây là sự khẳng định cho sự phát triển và không ngừng vươn lên của Trường trong giai đoạn vừa qua. 